\title{
Designing online species identification tools for biological recording: the impact on data quality and citizen science learning
}

\author{
Nirwan Sharma ${ }^{\text {Corresp.., }}{ }^{1,2}$ ， Laura Colucci-Gray ${ }^{3,4}$, Advaith Siddharthan ${ }^{5}$, Richard Comont ${ }^{6}$, René van der Wal ${ }^{2}$ \\ ${ }^{1}$ School of Natural and Computing Sciences, University of Aberdeen, Aberdeen, United Kingdom \\ 2 School of Biological Sciences, University of Aberdeen, Aberdeen, United Kingdom \\ 3 School of Education, University of Aberdeen, Aberdeen, United Kingdom \\ 4 Moray House School of Education, University of Edinburgh, Edinburgh, United Kingdom \\ 5 Knowledge Media Institute, The Open University, Milton Keynes, United Kingdom \\ 6 Bumblebee Conservation Trust, Stirling, United Kingdom \\ Corresponding Author: Nirwan Sharma \\ Email address: n.sharma@abdn.ac.uk
}

In recent years, the number and scale of environmental citizen science programmes that involve lay people in scientific research have increased rapidly. Many of these initiatives are concerned with the recording and identification of species, processes which are increasingly mediated through digital interfaces. Here we address the growing need to understand the particular role of digital identification tools, both in generating scientific data and in supporting learning by lay people engaged in citizen science activities pertaining to biological recording communities. Starting from two well-known identification tools, i.e. identification keys and field guides, we set out to investigate the psychological and educational features underlying species identification tasks, by comparing three digital interfaces designed to identify bumblebee species. The three interfaces varied with respect to whether species were directly compared or filtered by matching on visual features; and whether the order of filters was directed by the interface or a user-driven open choice. A concurrent mixed-method approach was adopted to compare how these different interfaces affected participants' ability to make correct and quick species identifications, and to better understand how participants learn through using these interfaces. We found that the accuracy of identification and quality of learning were dependent upon the interface type, the difficulty of the specimen on the image being identified and the interaction between interface type and 'image difficulty'. Specifically, interfaces based on filtering outperformed those based on direct visual comparison across all metrics, and an open choice of filters led to higher accuracy than the interface that directed the filtering. Our results have direct implications for the design of online identification technologies for biological recording, irrespective of whether the goal is to 
collect higher quality citizen science data, or to support user learning and engagement in these communities of practice. 


\section{Designing online species identification tools for biological}

\section{2 recording: the impact on data quality and citizen science}

\section{3 learning}

4 Nirwan Sharma ${ }^{1,5}$, Laura Colucci-Gray ${ }^{2,6}$, Advaith Siddharthan ${ }^{3}$, Richard Comont ${ }^{4}$, René van der

$5 \mathrm{Wal}^{5}$

$6{ }^{1}$ School of Natural and Computing Sciences, University of Aberdeen, Aberdeen, United

7 Kingdom

$8{ }^{2}$ School of Education, University of Aberdeen, Aberdeen, United Kingdom

9 K3nowledge Media Institute, The Open University, Milton Keynes, United Kingdom

$10{ }^{4}$ Bumblebee Conservation Trust, Stirling, United Kingdom

$11{ }^{5}$ School of Biological Sciences, University of Aberdeen, Aberdeen, United Kingdom

$12{ }^{6}$ Moray House School of Education, University of Edinburgh, Edinburgh, United Kingdom

$13 *$ Corresponding author

14 E-mail: n.sharma@abdn.ac.uk 


\section{Abstract}

16 In recent years, the number and scale of environmental citizen science programmes that involve

17 lay people in scientific research have increased rapidly. Many of these initiatives are concerned

18 with the recording and identification of species, processes which are increasingly mediated

19 through digital interfaces. Here we address the growing need to understand the particular role of

20 digital identification tools, both in generating scientific data and in supporting learning by lay

21 people engaged in citizen science activities pertaining to biological recording communities.

22 Starting from two well-known identification tools, i.e. identification keys and field guides, we set

23 out to investigate the psychological and educational features underlying species identification

24 tasks, by comparing three digital interfaces designed to identify bumblebee species. The three

interfaces varied with respect to whether species were directly compared or filtered by matching

on visual features; and whether the order of filters was directed by the interface or a user-driven

open choice. A concurrent mixed-method approach was adopted to compare how these different

interfaces affected participants' ability to make correct and quick species identifications, and to

better understand how participants learn through using these interfaces. We found that the accuracy of identification and quality of learning were dependent upon the interface type, the difficulty of the specimen on the image being identified and the interaction between interface type and 'image difficulty'. Specifically, interfaces based on filtering outperformed those based on direct visual comparison across all metrics, and an open choice of filters led to higher accuracy than the interface that directed the filtering. Our results have direct implications for the design of online identification technologies for biological recording, irrespective of whether the goal is to collect higher quality citizen science data, or to support user learning and engagement

37 in these communities of practice. 


\section{Introduction}

39 The relationship between science and society and the existing knowledge divide between expert

40 and lay knowledge continues to be subject to extensive debate (Mooney, Duraiappah \&

41 Larigauderie, 2013; Deshpande, Bhosale, \& Londhe, 2017). Citizen science as introduced by

42 Alan Irwin (Irwin, 1995) is a process of active engagement of the public in matters pertaining to

43 science and technology, with a view to influence policy developments. Citizen science has also

44 been associated with 'public participation in scientific research' (Cohn, 2008; Bonney et al.,

45 2009). Participation in such initiatives is meant to bridge the expert/lay knowledge divide (Hage,

46 Leroy \& Petersen, 2010), in the hope that by engaging the general public with scientific research,

47 society will benefit too (Riesch \& Potter, 2014).

48 The rapid advancement of computing technologies - especially mobile computing and the

49 Internet - has led to the emergence of a large number of citizen science projects, in a wide range

50 of domains including astronomy (e.g. classifying shapes of galaxies (Raddick et al., 2010)),

51 medical science (e.g. contributions to protein engineering for drug discovery (Cooper et al.,

52 2010) and cancer diagnostics (Schrope, 2013)) and environmental science (e.g. obtaining

53 biological records through identification of plant or animal species on images captured by

54 camera traps (Swanson et al., 2016) or by volunteers (Silvertown et al., 2015)). Through

55 initiatives of this kind, digital technologies have created new opportunities for engagement by a

56 much wider range of people with both the products and processes of scientific research. Hence,

57 the role of the public has changed from being simple 'recipients' of scientific developments to

58 acting as contributors to research, for example by helping to collect and categorise data for

59 scientific projects (Silvertown, 2009). 
60 While such new opportunities offer the prospect of scaling up scientific research activities, the

61 inclusion of lay people into the activities of professional scientists is not without problems. Two

62 perennial concerns reported in the literature are volunteer retention and differential ability

63 (Conrad \& Hilchey, 2011; Van der Wal et al., 2016; Austen et al., 2016, 2018), also described -

64 by Collins and Evans (2002) - as the 'dilemma of experience and expertise'. As the number of

65 stakeholders involved in research expands, the mediating role of digital tools may facilitate a

66 corresponding shift from a 'contributory expertise' model of engagement, based on the delivery

67 of data or expert knowledge, to an 'interactional expertise' model based on the integration of lay

68 and expert knowledge to form 'interactional expertise' (Collins \& Evans 2002). The difference

69 between the two types of expertise - contributory and interactional - lies with the degree of

70 stakeholders' immersion in core research practices. Whilst contributory expertise is based on the

71 provision of data and/or information to and from the experts, interactional expertise presupposes

72 the ability to act in a specialist domain of research, and thus interact with specialists even 'in the

73 absence of practical competence' (Collins \& Evans, 2002). By definition, interactional expertise

74 relies heavily on ongoing interaction with experts, and quickly becomes out of date when

75 interaction is not sustained. Two aspects are therefore paramount: (i) access to specialist

76 knowledge for sound decision-making, and (ii) level of sustained interaction with experts. Both

77 aspects are significantly affected by digital technologies. Thus, understanding the potential - and

78 pitfalls - of new digital interfaces, is urgently required in order to maximize the benefits for

79 citizen science (Kahn, Severson \& Ruckert, 2009). In this context, we study the differential

80 affordances of alternative digital interfaces for biological recording, whereby the interface acts as

81 the first realm of development of interactional expertise. 
82 Context of the study. This study is embedded in the context of biological recording. Heavily

83 dependent upon large-scale data collection over a wide geographical spread, biological recording

84 relies on incremental and cumulative data gathering. Traditionally, biological records have been

85 assembled by field naturalists - on their own accord and as part of natural history societies and

86 recording clubs (Burnett, Copp \& Harding, 1995; Miller-Rushing \& Primack, 2012), well before

87 the practice was set to become part of an academic discipline, and greatly preceding the advent

88 of digital technologies. Species identification skills were developed as part of 'field' immersion,

89 through familiarity with the context, sharing of annotations, conversations with local people and

90 direct observation. Key to identification was thus the combination of formal and

91 tacit/experiential knowledge acquired and maintained by the experienced recorder. Conversely,

92 citizen science projects extend traditional roles to include non-experts, i.e., people who may have

93 an interest in a topic but lack direct, relevant experience of field-note taking, recording or

94 identification. In addition, and as indicated above, digital tools enable geographical extension,

95 thus offering the possibility to answer pressing needs for data collection about species

96 distribution, while creating 'virtual' scenarios, in which large-scale data gathering occurs that

97 decouples people from places, short-cutting the long-held experience and tacit knowledge of the

98 field recorder. So, unlike for biological recording through the employment of traditional,

99 experiential expertise, digital tools can enable biological recording by simulating the process of

100 species identification via engagement with different types of interactive interfaces. In order to

101 understand the function of digital tools in biological recording and their effective design and use,

102 there is thus a need to investigate their role in creating communities of practice (Lave \& Wenger,

103 1991), whereby participants with different levels of training and different cognitive abilities

104 deliberate and debate, thereby creating opportunities to learn and think together (Bonney et al., 
105 2009; Dickinson, Zuckerberg \& Bonter, 2010). Communities of practice may range in size and

106 membership; and interaction amongst members may be in real-time, off-line or facilitated by a

107 virtual environment. Importantly, communities of practice are actively orientated towards

108 enhancing participants' learning practices, through request for information, problem solving,

109 coordination or seeking advice and experience (Lave \& Wenger, 1991). Within the realm of a

110 community of practice, digital interfaces can be conceived as 'tools' (Adedoyin, 2016) for

111 facilitating interaction, and evaluated from a user perspective on the basis of their 'suitability for

112 use' (e.g. the extent to which they align with users' psychological inclinations and offer accurate

113 as well as appropriate information), 'accessibility' (e.g. clarity and immediacy of use) and

114 'opportunity for learning' (e.g. availability to revisit prior steps and adapt new learning). In the

115 context of biological recording, digital technologies would thus enable, and in some way re-

116 create, the ongoing 'back and forth' of identification processes (e.g. looking for features;

117 comparing with previous knowledge, images, or experience), and intersection of different types

118 of knowledge which are held by different groups at different levels of immersion in the practices

119 of biological recording. Participants rely on learning support provided by identification tools,

120 such as identification keys and field guides, sometimes augmented through direct training from

121 other, more experienced, members or participation in community events. Through such

122 processes, participants face challenges deriving from the need to make sense of new information,

123 but they can also develop expertise such as handling scientific language for species

124 identification. In this view, two key aspects emerge as central to the focus of this study, and we

125 concentrate on these as a basis for designing interfaces which can favour progressively more

126 extended interactional opportunities. First, the design of interfaces needs to take account of both

127 communication formats and accuracy of identification tools, in order to support participation 
128 from different types of users. This aspect was investigated quantitatively by measuring user

129 performance and cognitive workload associated with exposure to new information. Second, the

130 interface needs to take account of the opportunities for participants to develop their own learning

131 and thus increase interactional expertise. This aspect was looked at qualitatively through

132 appraising the 'suitability of use' of digital tools, for example, by helping with the recognition of

133 new terms in practice; and/or revising one's choices during the process.

134 Designing digital identification tools. Two common tools for species identification are keys

135 and field guides. Identification keys provide novices with access to specialist taxonomic

136 knowledge; yet, as Lobanov (2003) pinpoints, they are notorious for their difficulty of use: 'Keys

137 are compiled by those who do not need them for those who cannot use them.' This has led to

138 increasing calls for more user-friendly identification keys to foster their adoption and use

139 (Stevenson, Haber \& Morris, 2003; Walter \& Winterton, 2007).

140 By contrast, field guides are usually popular tools for the casual consumers of taxonomic

141 information, and typically contain information derived from identification keys (Stevenson,

142 Haber \& Morris, 2003). Field guides exist in various forms, such as books, posters, flashcards

143 and brochures, and are often easier to use than identification keys (Scharf, 2008). Unlike keys,

144 field guides do not have as strict a design structure, and the presentation of information can

145 therefore vary considerably. They usually contain illustrations or photographs together with

146 written descriptions to aid species identification. Field guides may also include simple

147 keys/glossaries which can be presented as illustrations.

148 According to the theory of situated learning and legitimate peripheral participation in

149 communities of practice, any form of learning is contextual to the social setting where it is

150 practiced (Lave \& Wenger, 1991), and thus usability also depends upon the 'context of use' of an 
151 interface (ISO 9241-11, 1998). In this view, both types of identification tools, keys and guides,

152 may be assumed to be designed for the respective social setting of intended use (Hung, 2002;

153 Stevenson, Haber \& Morris, 2003), namely 'the lab', for identification keys and 'the field' for

154 field guides (Stevenson, Haber \& Morris, 2003). It can be argued that both identification keys

155 and field guides, ought to be 'fit for their purpose' as they have been widely used by

156 identification experts for hundreds of years (Scharf, 2008). As we will see later, features of both

157 tools were incorporated in the design of interfaces - and suitably evaluated - in order to address a

158 wider set of identification processes and assess how the use of digital interfaces can be

159 maximised for different types of users.

160 Online user participation. As indicated earlier, the availability of portable computing

161 technologies, such as mobile phones, digital photography and automated location tagging

162 through GPS, has notably extended the opportunities for biological recording. Participants can

163 contribute species data, typically captured through digital photographs, and there is growing

164 evidence of this in media sharing portals (e.g. Flickr, Facebook, YouTube) as well as in citizen

165 science projects (e.g. iSpot, iNaturalist, eBird), and these are increasingly being mined for

166 biodiversity research (Sullivan et al., 2009; Winterton, Guek \& Brooks, 2012; Gonella,

167 Rivadavia \& Fleischmann, 2015; Silvertown et al., 2015). However, while online identification

168 tools (keys/guides) are burgeoning, there is a surprising lack of user-centred design studies to

169 inform their development. Stevenson, Haber \& Morris (2003) reasoned that new Electronic Field

170 Guides should be developed using a combination of field guides and identification keys, with

171 potential applications in citizen science projects. The authors also highlighted the application of

172 learning theories and knowledge representation techniques in the design of these tools, as well as

173 the importance of testing them with end users as an essential requirement of any interactive 
174 software to improve usability (Stevenson, Haber \& Morris, 2003). These principles are likely

175 good starting points for research into the design of digital identification technologies aimed at

176 enhancing expertise of citizen science project users, and so were adopted in this study, detailed

177 as follows.

178 User-centred design for new online identification technologies. All identification keys work

179 on the basis of elimination, by filtering out possible species based on observed attributes. This is

180 less prone to error than the method of direct matching of attributes used in field guides,

181 especially for novices identifying unknown or unfamiliar specimens (Wills, Inkster \& Milton,

182 2015). Visual classification begins with the identification of individual attributes in a specimen,

183 which are subsequently combined and weighted (e.g. in the mind, or by using a key or guide) to

184 reach a decision (Treisman \& Gelade, 1980; Thompson \& Massaro, 1989; Lamberts \& Koen,

185 1995; Wills, Inkster \& Milton, 2015). So, if users are identifying new, multi-attribute objects,

186 like animal or plant species, direct matching may lead to misidentification because of the high

187 likelihood of decision-making based on irrelevant features (Wills, Inkster \& Milton, 2015).

188 Moreover, directing user attention - a distinctly limited resource (Lavie, 1995; Logan, 2002) - to

189 relevant attributes and distinguishing features that aid identification (Gibbon, Bindemann \&

190 Roberts, 2015) by highlighting key differentiation attributes, and using non-technical language

191 and representative pictures, become particularly important for novices who may be

192 inexperienced in identifying which attributes are relevant for a particular species identification.

193 For experts, information processing of stimuli takes place in the working memory (Baddeley,

194 1992), where they can access prior knowledge from their long-term memory, extract species

195 attributes and use that to arrive at an identification. Novices without in-depth species knowledge

196 rely on some form of training, which in online citizen science projects is typically delivered 
197 through an identification tool. As such, identification tools are designed for use on computing

198 devices, and well defined deterministic procedures or rules exist for species identification

199 (though subject to change over time with the discovery of new species, or new variations within

200 species); species identification for novice users can therefore be modelled as a structured

201 problem in interface design (Jonassen, 2000). Taking such principles into account, this study first

202 proceeded by considering the methods of elimination using identification keys, and using

203 illustrations and language as well as contextual information derived from a field guide with

204 progressive disclosure (showing information when it may be needed). Specifically, we

205 prototyped two interactive interfaces - 'Feature selection' and 'Decision tree' -the building

206 blocks of which were taken from an existing 'Field guide'; the latter in turn acting as control.

207 These interfaces vary with respect to several generic characteristics of identification keys: the

208 number of entry points (single or multi access) and number of states (dichotomous [two states] or

209 polytomous [more than two states] (Lobanov, 2003); whether the user or the interface directs

210 decision-making; and whether the interface supports filtering. See Table 1 for a summary of the

211 key differences between the prototyped interfaces.

212 In the remaining part of this paper, we report on a systematic evaluation of two interactive

213 prototypes (and their associated field guide), with a sample of semi-experienced users, focussing

214 on two key aspects: a) decision-making - how the accuracy of identification, time taken and

215 mental workload of a user is affected by the choice of interface; and b) quality of learning

216 process - how the different interfaces facilitate novices in sophisticated thinking processes that

217 require the combination of generic prior skills (e.g. image recognition, colour and size

218 perception, language processing), with task-specific decision-making moderated by the

219 interfaces (as described in Table 1). Such comparative assessment would provide central 
220 information on design principles and the accuracy of learning pathways enabled by each

221 interface type.

\section{Materials and Methods}

223 Focal species group. We selected bumblebee species in the UK as the taxonomic focus of this

224 study. Bumblebees represent a species group which requires careful differentiation of visual

225 features for accurate identification. There are 22 species (Siddharthan et al., 2016) in the UK that

226 are identifiable based on different visual features, including the colour of the tail, size of the face,

227 shape of antennas, different colour band patterns on their thorax and abdomen, and presence of

228 pollen baskets on the hind legs. Combinations of these features assist the classification of

229 bumblebees into different species as well as to identify a specimen as female (queen/worker) or

230 male. Not all features are clearly visible in all species or in all circumstances, and this is

231 potentially a bigger issue when performing identification using a photograph rather than in the

232 field. Some of the species are very similar; for example, only close inspection of the colour of

233 the hairs on the hind legs can distinguish a Red-tailed bumblebee (Bombus lapidarius) from a

234 Red-shanked carder bee (Bombus ruderarius).

235 Images. We randomly selected six images from a real world citizen science project, BeeWatch

236 (Van der Wal et al., 2015), with two levels of difficulty due to some bumblebee species being

237 intrinsically harder to identify than others. Those images were selected from a large subset for

238 which BeeWatch had solicited 10 independent identifications by BeeWatch users, which was

239 used to develop a Bayesian verification algorithm (Siddharthan et al., 2016). All images were

240 also identified by a bumblebee expert and we selected three difficult images where fewer than 
$24150 \%$ of users identified the species correctly (compared to the expert), and three easy images

242 where more than $80 \%$ of users identified the species correctly.

244 Interfaces. The three interfaces used in the study and described in Table 1 are illustrated in Figs

245 1-3. In the UK, the Bumblebee Conservation Trust (BBCT; bumblebeeconservation.org)

246 provides a bumblebee identification guide, designed using relatively simple language and

247 containing illustrations of bumblebee species, with the aim to help members of the general public

248 to perform the task of bumblebee identification in the field (see Fig 1). We used the images and

249 textual information from this guide to develop an interface employing the principles of decision

250 trees, shown in Fig 2 with an example workflow of an identification process. Each screen asks

251 the user to select an option in a predetermined order, such that cognitively easier options are

252 offered early on. Users can backtrack on a decision by following the "back" link at any stage.

253 Using the same images and textual information, we also designed a tool employing feature

254 selection (Fig 3). Users can select any features they are confident about, and their selection will

255 shade out options that do not match. Features can be unselected, or their values changed at any 256 point.

257 The interfaces studied incorporate design principles from both Field guides and Identification

258 keys. The first set of principles considered the 'context of use' of the interfaces with associated

259 behavioural, aesthetic and anatomical characteristics. The second set of principles considered a

260 hierarchy of significant features which are deemed to be 'distinctive' for particular species.

261 Hence, the design of the interface considered both holistic and analytical functions of the

262 identification process. In addition, our study involved a species group which is neither too simple

263 (i.e. few species with easy to identify characteristics) or too complicated (i.e. a species group 
264 such as moths for which $\sim 2,500$ species are known to occur in the UK) to identify. The

265 developed interfaces had design parallels in other species identification tools. For instance, the

266 Decision tree interface has design elements (single access key design) similar to the Merlin Bird

267 ID mobile application (http://merlin.allaboutbirds.org/) and the Natural History Museum

268 Bumblebee Identification key (http://www.nhm.ac.uk/research-

269 curation/research/projects/bombus/key_british_colour.html), while the Feature selection

270 interface has design elements of multi-access keys such as interactive keys on iSpot

271 (www.ispotnature.org/webkeys/index.jsp) and Discover Life (www.discoverlife.org). Some

272 citizen science projects even provide multiple types of interactive tools, such as Go Botany

273 (https://gobotany.newenglandwild.org), which offers a dichotomous key as well as a multi-

274 access key based design (Farnsworth et al., 2013). For the purpose of this study, we looked more

275 closely at design choices in relation to data quality and user-learning, thus contributing empirical

276 findings to this growing area of practice.

278 Participants. Participants were drawn from students on the MSc Ecology or MSc Applied

279 Marine and Fisheries Ecology degree at the University of Aberdeen. Participation was couched

280 as an opportunity for wider learning on citizen science and to contribute to ongoing research. All

281 participants offered their voluntary participation, showing self-selection, and took part in fixed

$28230-40$ min slots with the experimenter (the lead author). Each participant was given $£ 10$ in cash

283 as a token of our appreciation for their participation. In addition, a collective session was

284 arranged with the participants following the experiment to highlight the results of the exercise

285 and introduce them to the role of citizen science in nature conservation. The sample size was

286 limited to eighteen participants to keep the data manageable (108 identification tasks with think- 
287 aloud and screen recording data) (Anderson \& Vingrys, 2001). The study was approved by the

288 University of Aberdeen's ethics committee, and all participants provided written informed 289 consent.

290 Participants differed in their level of English language skills (7 international students of which 2

291 from English-speaking countries, and a further 11 native English speakers from the UK). The

292 median age of participants was 23 years. Eight participants were female and the other 10 were

293 male. Almost all had some experience with species identification of plants or animals other than

294 insects (due to exposure to this during their biology degrees), while 13 participants also had

295 some experience with insect identification. None of them were experienced in bumblebee species

296 identification and therefore could all be considered novices for this species group.

297 Masters level students are routinely exposed to online systems like digital libraries (Ebrary),

298 databases (Scopus, Web of Science) and learning environments (Blackboard, used by all

299 University of Aberdeen students); and regularly use digital systems for their assignments,

300 tutorials and presentations, including word processors, spreadsheets, graphical software (notably

301 Powerpoint) and statistical software. We therefore expected our sample of users to be able to

302 provide insights into the role played by a respective interface in reaching a (positive) species

303 identification, as well as feedback on the role of the interface in mediating their cognitive load.

305 Experimental design. We used a concurrent mixed methods design involving bumblebee

306 identification tasks, workload questionnaires, think aloud protocol and screen recordings. Before

307 commencing, participants were given a brief background to the study, informing them that it

308 involved completing bumblebee identification tasks using three different interfaces shown on a 
309 computer in order to assess the usability and effectiveness of these interfaces. All the participants

310 then completed six identification tasks. Each task concerned the use of one of the three interfaces

311 and one of the six photographs of bumblebees used in the study (and thus six photographs per

312 participant), in a manner counterbalanced across participants to control for order of identification

313 tasks (see Appendix 1) whilst ensuring all interfaces types were used (twice) by each participant.

314 The participants were given a practice run with each interface when they encountered it for the

315 first time during the experiment. The following steps were then performed for each identification 316 task:

317 1. The participant was given an image of a bumblebee printed at high resolution on paper.

318 2. An identification interface was shown on a laptop, with a mouse attached for easier

319 interaction.

3203 . The participant was asked to identify the bumblebee species in the image by using the

321 interface and to subsequently write down the identification on an answer sheet. The

322 identification process was timed, but it was stressed that the goal was to get an accurate

323 result, and thus to take as much time as required.

324 4. During the identification process the participant was asked to think aloud and this was

325 recorded.

326 5. A paper version of the NASA-TLX subjective workload questionnaire (see below) was filled out by the participant for the completed identification task.

329 Experimental Measures. We used quantitative methods to assess accuracy, time taken and 330 cognitive workload, and a think-aloud protocol to collect qualitative data. 
331 Accuracy: Task accuracy was assessed by comparing the identification provided by the

332 participant to the expert identification (provided by a Bumblebee expert through the BeeWatch

333 platform).

334 Time: Task time was the total time taken to complete a single identification task (i.e. one photo

335 on one interface) measured in seconds.

336 Workload: As identification is a problem-solving task, we wanted to obtain relative measures of

337 'how much mental work' was required by the participants to perform the task. We used the

338 NASA-TLX subjective workload questionnaire (Appendix 2), a workload assessment tool (Hart

$339 \&$ Staveland, 1988) that has been widely used for assessing workload measures for Human

340 Computer Interaction (HCI) research (Hart, 2006). The assessment tool provides a weighted

341 average across six dimensions of mental workload: Mental demand, Physical demand, Temporal

342 demand, Performance, Effort, and Frustration. In the first part of the questionnaire, participants

343 give - for each of the six dimensions - a subjective rating (scale $0-100$ ) per identification task. In

344 the second part, they assign weights to the dimensions by conducting a pairwise comparison for

345 all possible combinations of the six dimensions. For each pairwise comparison, participants

346 select which of the two dimensions is perceived to be the most important contributor towards the

347 workload for the task. The selections are then used to assign weights from 0-5 for each

348 dimension, by counting the number of times each dimension is selected as being the most

349 important across all pairwise comparisons. For example, if Mental Demand is selected as most

350 important in each of the five possible pairwise comparisons, then it is assigned a weight of 5.

351 These weights are then multiplied with their associated ratings and added to derive at the total

352 workload score, which is subsequently divided by 15 (total sum of the weights) to obtain an

353 average workload score for each task. The participants were explained the NASA TLX rating 
354 scale and its six dimensions after the first task, and were also provided with a 'workload

355 information sheet' for reference.

356 Think Aloud: Participants were asked to think aloud and verbalise their thought processes while

357 performing the identification task (Ericsson \& Simon, 1980) and this was recorded. Think aloud

358 is a protocol widely used in research concerned with learning processes (Leow \& Morgan-Short,

359 2004) as well as usability studies (McDonald, Edwards \& Zhao, 2012), and is found to be highly

360 suited for capturing user thinking processes without negatively affecting mental workload or

361 performance measures (Young, 2005; Fox et al., 2011; Pike et al., 2014). Some of the issues of

362 the think-aloud method, such as reactivity, verbal ability of participants and validity, were

363 addressed by following standardised approaches from the literature. These included giving a

364 practice run on the tasks, employing 'keep talking' probes, capturing additional data in the form

365 of screen recordings, and using a research task which is not 'automatic' for the participants

366 (Young, 2005). The experimenter did not interact during the identification process; however, if

367 participants went silent during the task, they were asked to resume talking.

368 Data was analysed using grounded theory (Wagner, Glaser \& Strauss, 1968) by firstly coding the

369 data to identify patterns of use of the interfaces, with each observation annotated with the

370 relevant image and interface. These patterns of interface use helped in identifying the most

371 commonly followed steps taken by participants during identification tasks across each interface

372 and image combination. Further, 'suitability of use' of each interface was determined by

373 investigating three dimensions, derived from insights provided by the literature (e.g. Adedoyin,

374 2016), namely usefulness (i.e. whether the interface facilitated progress or not), accessibility

375 (ease of use in locating information on the interface) and opportunity for learning (mobilising

376 prior and extended knowledge). These annotations allowed us to not only obtain information on 
377 the interactions with the interface but, most importantly, to also reveal the thinking processes

378 behind those interactions. This included looking at the identification strategies adopted by

379 participants (e.g. colour matching vs. evidence-based reasoning) and the opportunities offered by

380 the interface to verify possible mistakes (e.g. by going back) and to combine additional or new

381 options (e.g. colour and position).

382 Statistical Approach. Quantitative analyses were run in SPSS Version 24 (IBM Corp., 2016).

383 Accuracy, Time and Workload data were analysed using Generalised Linear Mixed Models

384 (GLMMs). Accuracy data were fitted using a binomial distribution with logit function, while

385 Time and Workload data were fitted using normal distributions with identity function. Image

386 difficulty (Easy and Difficult), Interface type (Field guide, Feature selection and Decision tree)

387 and the interaction between them were fitted as fixed effects, and Participant was included as a

388 random effect. Post hoc comparisons were computed (using EMMEANS TABLES) for the

389 interaction of Image difficulty and Interface type with Least Significance Difference (LSD)

390 adjustment.

391 Results

392

393 Accuracy. Our first hypothesis (H1) was that species identification accuracy is influenced by

394 interface design, with interactive keys resulting in more accurate identifications than a field

395 guide design, and with easier images resulting in higher accuracy than difficult images regardless

396 the interface used.

397 Interface type $\left(\mathrm{F}_{2,102}=3.88, \mathrm{p}<0.05\right)$, Image difficulty $\left(\mathrm{F}_{1,102}=5.02, \mathrm{p}<0.05\right)$ and the interaction

398 between Interface type and Image difficulty $\left(\mathrm{F}_{2,102}=4.39, \mathrm{p}<0.05\right)$ all explained significant 
399 amounts of variation in accuracy of participants' species identification (Fig 4a), revealing that it

400 was not simply the type of interface or image difficulty alone that influenced identification

401 accuracy, but it was their combination that mattered. Overall, our participants indeed achieved

402 lower average accuracy with difficult images (mean accuracy=0.24) compared to easy images

403 (mean accuracy $=0.48$ ). Post hoc analysis, conducted to interpret the interaction, showed that for

404 easier images participants achieved significantly higher accuracy using the Feature selection

405 interface compared to the Field guide $\left(\mathrm{t}_{102}=2.26, \mathrm{p}<0.05\right)$ and Decision tree $\left(\mathrm{t}_{102}=4.29, \mathrm{p}<0.0001\right)$

406 interfaces. For difficult images, the Decision tree interface was significantly better than the Field

407 guide $\left(\mathrm{t}_{102}=2.01, \mathrm{p}<0.05\right)$. No other contrasts (within either category of image difficulty) were

408 significant.

409 Time taken. Our second hypothesis (H2) was that the time taken for species identification

410 differs among the three focal interfaces and between image difficulty types (easy/difficult), with

411 the decision tree (that orders questions by difficulty) taking the shortest time and the field guide

412 (that offers no interaction) taking the longest, and with easier images taking less time than

413 difficult ones.

414 Contrary to our expectation $(\mathrm{H} 2)$, the type of interface did not influence the length of time it took

415 participants to complete an identification task $\left.\left(\mathrm{F}_{2,102}=1.21, \mathrm{p}=0.30\right)\right)$. Image Difficulty mattered,

416 however $\left(\mathrm{F}_{1,102}=4.43, \mathrm{p}<0.05\right)$ ), with easier images (mean 133 seconds) taking less time to

417 identify than difficult ones (mean 157 seconds).

418 Workload. Our third hypothesis (H3) was that the perceived workload differs among the three

419 interfaces and between the two image types, in ways similar to $\mathrm{H} 2$, with the decision tree being

420 easiest to use, as it asks questions in order of difficulty and guides the user to an answer, and the

421 non-interactive field guide being the hardest. 
422 Our analysis of workload suggested differences between the three Interface types $\left(\mathrm{F}_{2,102}=3.81\right.$,

$423 \mathrm{p}<0.05)$, but also some support for the notion that no one interface generated the lowest work

424 load, but that this depended on Image difficulty (; Interface type $\times$ Image difficulty: $\left(\mathrm{F}_{2,102}=2.92\right.$,

$425 \mathrm{p}=0.06$; Image difficulty: $\left(\mathrm{F}_{1,102}=3.09, \mathrm{p}=0.08\right)$. Post-hoc analysis revealed that for easier images

426 participants perceived significantly lower workload using the Feature selection tool compared to

427 Field guide $\left(\mathrm{t}_{102}=2.21, \mathrm{p}<0.05\right)$. For difficult images, participants perceived significantly lower

428 workload for the Decision tree tool compared to both the Field guide $\left(\mathrm{t}_{102}=2.81, \mathrm{p}<0.05\right)$ and

429 Feature selection $\left(\mathrm{t}_{102}=2.09, \mathrm{p}<0.05\right)$. No other contrast statements (within category of difficulty)

430 revealed significant differences.

431 Think aloud. While our quantitative data partially confirmed our hypotheses (H1-H3), they also

432 produced several unexpected findings. Our qualitative data were used to subsequently help

433 interpret the above-reported findings in greater depth by looking at the nature of the thinking and

434 learning processes.

435 Field guide: Because interactive filtering - which is normally used to limit the number of relevant

436 species to consider - could not be done with the field guide, participants tended to rely on

437 matching colour patterns first, as a means to identify a bumblebee specimen. Visually, these

438 appeared to be the most salient features. This strategy only proved useful in cases where the

439 colour pattern was (a) identified correctly and (b) where it reduced the candidate species to a

440 small subset, such as for participant 16 ("colour of the tail black, so it's all black - we will go

441 through the pictures"); and participant 10, who went through the guide to determine which ones

442 had a red tail - a rather specific feature (“...maybe it's a red tailed bumblebee as looks more like

443 that sort of.."), and then said "I quite like that one"”, and making a resolute (and correct) choice. 
444 Yet, in many cases there appeared to be too many species with similar overall appearances to

445 allow functional matching. Participants experienced frustration due to lack of filtering, as stated

446 by participant 1 (“...I don't know how to narrow it down more based on the pictures...”). When

447 some motivated participants subsequently tried to identify a specimen based on other attributes

448 (e.g. pollen baskets, distinguishing attributes), the total number of attributes to be considered

449 increased, often beyond the capacity of participants to process information in their minds (i.e.

450 exceeding working memory). This repeatedly led to 'guesses' whilst overlooking attributes

451 critical to the identification. For instance, participant 6, after poring over numerous different

452 attributes (colour pattern, pollen basket, wing colour, yellow band at the bottom of the thorax,

453 size of face), specifically considered the correct category of cuckoo bumblebees ("it's got just

454 dusky wings so it could be a cuckoo bumblebee"), but then dropped this understanding, focussed

455 on other, less useful attributes for this particular identification ("It does have yellow band so

456 garden bumblebee”). This incorrect identification was reinforced by confusing a large face for a

457 long face (“it's got quite a large face, it's not a small looking bumblebee, I think it's the garden

458 bumblebee”), finally deriving the wrong species identification. So, in the absence of direct

459 experience in the field, the quality of decision-making using the Field guide was largely

460 dependent upon participants' ability to recognize colour patterns and combine further attributes

461 without 'losing the plot'; thereby explaining why mean accuracy (Fig 4a) was relatively high for

462 easy images and very low for difficult ones.

463 Decision tree: As with all decision trees, this interface had hierarchical and interface-directed

464 interactive filtering, in our case from easy attributes to more difficult ones (i.e. from overall

465 colour to colour patterns to distinguishing attributes), and with each feature decision on a

466 separate page. Overall, interactive filtering led to a reduced workload as compared to the Field 
467 guide (Fig 4c). This was particularly evident for colour patterns, with participants being able to

468 readily limit choice, as for participant 3 (“...can't see any yellow but not sure if that's due to the

469 angle of the picture but I am gonna go with..."). Indeed, this interface attracted the lowest

470 perceived workload for difficult images (Fig 4c), for which colour patterns could be rather

471 complex.

472 Whilst this interface type facilitated high accuracy for difficult images, the Decision tree had the

473 lowest accuracy for easier species, often because participants identified the distinguishing

474 attributes incorrectly at the final stage. For example, participant 12 tried to match the remaining

475 illustrations by colour (“...because it's got quite bright orange on the thorax it could be moss

476 carder bee...") rather than using the distinguishing attributes as given on the final page.

477 Similarly, participant 9 first appeared to have identified the specimen based on the distinguishing

478 attribute (“... rows of black hair on abdomen - I guess it's that...”), but then gradually changed

479 that decision by diverting attention to the illustrations ("...ok these two require microscopic

480 examination to separate....I do see black rows... I don't think its hairs really....if I had to

481 choose... but that's a total guess from me...") while continuously matching the image to

482 illustrations, reinforcing the wrong choice and highlighting frustration with the choice eventually

483 made.

484 In uncommon cases where remembering prior colour selections may have been less critical for

485 making an accurate identification (which occurred only for one of the difficult images where the

486 specimen was all black, eliminating the need to remember or match on the basis of colour

487 patterns), participants were able to focus their attention on the distinguishing attribute (long vs

488 short face), as illustrated by participant 8 (“...if I was feeding from a flower like that I think I 
489

490 with this one yeah!!..." ").

491 These observations highlight that even though participants were able to identify easier attributes

492 based on colours and colour patterns correctly, and interactive elimination reduced their

493 cognitive workload, the interface did - in general - not offer visual access to prior. As these

494 earlier selections were not visible, participants seemed to forget previously selected attributes

495

and reverted back to pattern matching based on colours, rather than matching the distinguishing

496

attributes given by the interface, which often led to incorrect identification. Further, while

497

498

499

500

501

502

503

504

505

506

507

508

509 ("wings... clear... pollen basket... not too sure"). Additionally, the interface updated results from

510 each selection, which helped participants to monitor their own progression along the

511 identification path, as highlighted by participant 17 who first verified the results of previous 
512 selections (“...leaves three species: one cuckoo, one rare and one common...”), then selected a

513 remaining attribute (“....wings... look clear to me...”) to subsequently verify the results (“...one

514 rare... one common...”). Such iterative interaction helped the participants to reduce to a small

515 subset of similarly patterned species.

516 When participants seemed confused (due to image quality or colour variation) while identifying

517 based on patterns, they could review their previous selections either by searching for other

518 attribute options in drop down menus, or by de-activating confusing attributes. For example,

519 participant 11, who first selected an attribute (thorax) and said “...potentially could be the tree

520 bumblebee..." but then de-activated this filter - as the colour from the image did not exactly

521 match the colour in the drop-down list - and selected a different attribute ("...abdomen is white

522 and black...") to get the same result (...which again is the tree bumblebee...). Such reviewing

523 helped participants to verify prior selections by iteratively going back and forth for similarly

524 patterned species, which facilitated their progression to identifying using distinguishing

525 attributes. For example after verifying pattern selections for similar species, participant 4

526 progressed to identifying based on distinguishing attributes by reducing the number of candidate

527 species from three to two (“...never has black hairs so probably not that one...") and then to one

528 (“...variable patches...”), highlighting the Feature selection tool's ability to foster continued

529 progression and user confidence.

\section{Discussion}

531 This study looked at the role of digital interface design in citizens' engagement with species

532 identification and, in particular, the learning processes which may sustain biological recording

533 and associated scientific research as well as greater public participation in respective citizen 
534 science initiatives (Riesch \& Potter, 2014). A first important finding emerging from the study

535 was the heavy reliance on visual classification as a process through which the human eye attends

536 to specific features in order to make decisions about species identification. Notably, whilst this

537 type of observation is common for field naturalists (Ellis, 2011), direct matching of illustrations

538 may lead to errors by users with limited levels of expertise (Austen et al., 2016), as they may

539 focus on irrelevant attributes perceived to be important for identification. Echoing prior research

540 (Wills, Inkster \& Milton, 2015), our results highlight this risk to be particularly significant with

541 field guides, as these emphasize direct matching, a principle that leads to both increased

542 cognitive workload and low accuracy on the identification task in novices.

543 So, while field guides may be the most common tools for identification, they may be prove

544 difficult to use for novices and have the potential to lead to errors in the context online species

545 identification. Providing interactive elimination of choice reduced cognitive workload and

546 helped participants to make progress during a classification process. This was evident for both

547 Decision tree and Feature selection tools, where the interface helped participants to reduce their

548 choice by selecting features. Both types of interactive eliminations, directed and open choice,

549 were useful for reducing the workload, as participants were able to limit choices to a subset of

550 similarly patterned species. Cognitively, the option to select individual attributes is useful for

551 identifying unknown objects (Treisman \& Gelade, 1980; Thompson \& Massaro, 1989; Wills,

552 Inkster \& Milton, 2015), as it allows the interface to direct user attention to specific features as

553 well as reduce choices with each selection, and our results validate this for the task of bumblebee

554 identification.

555 In the case of open choice, which was available in our Feature selection tool, the user

556 progression may be easier for self-learning. As our findings also showed, when following a 
557 hierarchy of attributes, there is a risk for the identification going wrong due to overlooking or

558 excluding particular attributes. This is notably true for novices, who may lack in confidence or

559 sensitivity to particular features, but also the case for 'experts' who may be erring on the side of

560 caution when they are aware of the level of complexity and intra-species variability (Austen et

561 al., 2016). So, our findings seem to support the idea that open choice of filters may be more

562 applicable for engaging users with different level of expertise, as they do not rely on a pre-

563 defined hierarchy based on particular design assumptions about the user's experience or

564 expertise (Walter \& Winterton, 2007).

565 A general appraisal of our findings would thus suggest that in order for digital tools to fulfil their 566 promise of increasing participation in citizen science projects (Irwin, 1994), it is important for

567 novices and experts alike to be able to explore and learn about their own visual experiences. For

568 this purpose, it may be important for all participants to iteratively attend to attributes for visual

569 information processing in order to identify specimens correctly. This is even more relevant when

570 platforms may be accessed from a wide geographical scale, calling for the identification of

571 unfamiliar species. Even though all three interfaces had the provision for users to iteratively

572 attend multiple attributes, Feature selection made this easiest (single page, with visual shading

573 out of filtered options) and hence participants readily went back and forth during the

574 identification process in order to verify possible mistakes and learn. Combining the advantages

575 of interactive filtering and easier engagement, feature selection design seems to promote both

576 user learning and accuracy. Although our Decision tree design allowed participants to achieve

577 similarly high accuracies for difficult images at a lower perceived workload than was the case

578 using Feature selection, the latter interface proved far superior for easier images, and hence a

579 better approach for classification tasks with variable levels of difficulty. To improve the decision 
580 tree design accuracies, human intelligence can be augmented with machine intelligence as in the

581 case of mobile applications like the Merlin bird identification app where big data analytics is

582 used to limit results by location and time of the year. However, such an approach, requires

583 reliable and fine-grained species distribution data to meaningfully reduce errors (Farnsworth et

584 al., 2013) - a position that may not be within easy reach for many species groups other than birds

585 (Amano, Lamming \& Sutherland, 2016).

586 A range of documents unfold best practices and guidelines for the design of identification tools

587 (Walter \& Winterton, 2007; Leggett \& Kirchoff, 2011; Farnsworth et al., 2013). Yet, we note,

588 these are largely based on experiential knowledge, and very few scientific studies exist which

589 test elements of keys or field guides with users (Stucky, 1984; Morse, Tardival \& Spicer, 1996;

590 Hawthorne, Cable \& Marshall, 2014; Austen et al., 2016). This problem is compounded by the

591 exponential growth of citizen science projects incorporating identification tools, with multiple

592 designs regularly present even within the same initiative (Farnsworth et al., 2013). Our findings

593 may allow programmes to limit noise in citizen science data collected using embedded

594 identification tools (see Van der Wal et al., 2016 for an evaluation of our Feature selection tool

595 embedded in a live citizen science programme), whilst potentially fostering the development of

596 standardized identification technologies and learning. Greater awareness of design principles and

597 learning processes in digital interfaces are thus essential for the identification of species groups

598 heavily reliant on experts for identification - a resource known to be limited and diminishing

599 (Walter \& Winterton, 2007; August et al., 2015).

600

601 Species identification is a complex scientific task for which skills and expertise are gained

602 through years of experience in the field as well as through training, either online or with other 
603 members of the community. Such learning requires cognitive support from identification tools

604 and is thus an essential requirement for the new forms of online participation in community

605 learning. Hence, there is a need to focus on user-centred design with emphasis on both usability

606 and accuracy, which can engage new members in learning species identification skills while

607 facilitating scientific research, both essential for citizen science. Returning to the framework of

608 Collins and Evans (2002), our research revealed that feature selection is a tool which allows non-

609 experts to flexibly accrue relevant expert knowledge, enabling interactivity as if in a community

610 of practice.

\section{Conclusion}

612 The aim of the study presented was to understand how digital interfaces may be able to enhance

613 self-learning processes whilst participants are conducting a relatively complex task of species

614 identification. The main findings are that open choice of filters were more user-friendly and

615 improved user performance in the task as compared to interfaces which emphasised direct

616 matching or hierarchical reasoning. Such findings have a number of important implications.

617 First, by focusing on design principles fostering identification tasks using computing

618 technologies, we sought to widen our perspective on citizen science. We moved from the original

619 idea of citizens working as scientists (Irwin, 1996; Riesch \& Potter, 2014) to a more flexible and

620 hybrid model of citizens and future scientists operating and learning as part of extended

621 communities of practice (Lave and Wenger, 1991). From this perspective, interdisciplinary

622 dialogue across computing science, ecology and education was paramount to pave the way to

623 more articulated processes of social learning centred on real-life problems (Sol, Beers and Wals,

624 2013). A second implication is that our findings run counter to the idea that citizens need to

625 'understand the science first' - as proposed by conventional models of public understanding of 
626 science (Hage, Leroy and Petersen, 2010) - in order to be able to partake in scientific research.

627 Rather, our study pointed to the importance of developing awareness and make use of the very

628 human process of sensorial perception in science (Colucci-Gray \& Camino, 2016), both in order

629 to learn and to design optimal interfaces.

630 As we have seen through the study and the findings, the possibility of iteratively attending to the

631 attributes of a photographed specimen was found to be extremely valuable for learning and user-

632 progression. These findings highlight that feature selection, which utilised these design

633 principles effectively, may be one of the methods which can be used to productively integrate

634 existing species identification knowledge, and allow novices to perform certain identification

635 tasks readily and accurately. Finally, our findings provide support for the possibility of using

636 digital tools to reinforce interactional as opposed to contributory expertise.

637 Given the prevalence of photo-submission-based species identification programmes, there is 638 scope for extending the findings from this study to the design of interfaces that may be used in

639 hybrid contexts of research and practice, such as in agro-ecology or urban gardening contexts.

640 Following Kahn, Severson and Ruckert (2009), our findings invite further research to fully

641 embrace the potential for digital tools in citizen science projects to increase public's attention to

642 environmental matters as well as greater engagement with and participation in science.

\section{References}

644 Adedoyin ACA. 2016. Deploying virtual communities of practice as a digital tool in social work:

645 a rapid review and critique of the literature. Social Work Education 35:357-370. DOI:

$646 \quad 10.1080 / 02615479.2016 .1154660$. 
647 Amano T., Lamming JDL., Sutherland WJ. 2016. Spatial gaps in global biodiversity information 648 and the role of citizen science. BioScience 66:393-400. DOI: 10.1093/biosci/biw022.

649 Anderson AJ., Vingrys AJ. 2001. Small samples: does size matter? Investigative Ophthalmology $650 \&$ Visual Science 42:1411-3.

651 August T., Harvey M., Lightfoot P., Kilbey D., Papadopoulos T., Jepson P. 2015. Emerging 652 technologies for biological recording. Biological Journal of the Linnean Society 115:731-749. 653 DOI: $10.1111 /$ bij.12534.

654 Austen GE., Bindemann M., Griffiths RA., Roberts DL. 2016. Species identification by experts 655 and non-experts: comparing images from field guides. Scientific Reports 6:33634. DOI: $656 \quad 10.1038 /$ srep33634.

657 Austen GE., Bindemann M., Griffiths RA., Roberts DL. 2018. Species identification by 658 conservation practitioners using online images: accuracy and agreement between experts. PeerJ 659 6:e4157. DOI: $10.7717 /$ peerj.4157.

660 Baddeley A. 1992. Working memory. Science 255:556-9. DOI: 10.1126/SCIENCE.1736359.

661 Bonney R., Ballard H., Jordan R., McCallie E., Phillips T., Shirk J., Wilderman CC. 2009. 662 Public Participation in Scientific Research: Defining the Field and Assessing Its Potential for 663 Informal Science Education. A CAISE Inquiry Group Report.

664 Burnett J., Copp C., Harding P. 1995. Biological recording in the United Kingdom-present 665 practice and future development. Volume 1 Report. London: Department of the Environment.

666 Cohn JP. 2008. Citizen Science: Can Volunteers Do Real Research? BioScience 58:192. DOI: $66710.1641 /$ B580303. 
668 Collins HM., Evans R. 2002. The Third Wave of Science Studies: Studies of Expertise and

669 Experience. Social Studies of Science 32:235-296. DOI: 10.1177/0306312702032002003.

670 Colucci-Gray L., Camino E. 2016. Looking Back and Moving Sideways: Following the

671 Gandhian Approach as the Underlying Thread for a Sustainable Science and Education. Visions

672 for Sustainability 6:23-44. DOI: 10.13135/2384-8677/1869.

673 Conrad CC., Hilchey KG. 2011. A review of citizen science and community-based

674 environmental monitoring: issues and opportunities. Environmental Monitoring and Assessment

675 176:273-91. DOI: 10.1007/s10661-010-1582-5.

676 Cooper S., Khatib F., Treuille A., Barbero J., Lee J., Beenen M., Leaver-Fay A., Baker D.,

677 Popović Z., Players F. 2010. Predicting protein structures with a multiplayer online game. Nature 678 466:756-60. DOI: 10.1038/nature09304.

679 Deshpande, D., Bhosale, N., and R. Jagannathrao Londhe 2018. Enhancing Academic Research 680 With Knowledge Management Principles. New Delhi: IGI global partnerships.

681 Dickinson JL., Zuckerberg B., Bonter DN. 2010. Citizen Science as an Ecological Research 682 Tool: Challenges and Benefits. Annual Review of Ecology, Evolution, and Systematics 41:149683 172. DOI: 10.1146/annurev-ecolsys-102209-144636.

684 Ellis, R., 2011. Jizz and the joy of pattern recognition: Virtuosity, discipline and the agency of 685 insight in UK naturalists' arts of seeing. Social Studies of Science, 41(6), pp.769-790.

686 Ericsson K., Simon H. 1980. Verbal reports as data. Psychological review 87:215-251. DOI:

$687 \quad 10.1037 / 0033-295 X .87 .3 .215$. 
688 Farnsworth EJ., Chu M., Kress WJ., Neill AK., Best JH., Pickering J., Stevenson RD., Courtney

689 GW., VanDyk JK., Ellison AM. 2013. Next-Generation Field Guides. BioScience 63:891-899.

690 DOI: $10.1525 /$ bio.2013.63.11.8.

691 Fox M., Ericsson K., Bulletin RB-P., 2011 U. 2011. Do procedures for verbal reporting of

692 thinking have to be reactive? A meta-analysis and recommendations for best reporting methods.

693 Psychological Bulletin 137:316-344.

694 Gibbon GEM., Bindemann M., Roberts DL. 2015. Factors affecting the identification of

695 individual mountain bongo antelope. PeerJ 3:e1303. DOI: 10.7717/peerj.1303.

696 Gonella P., Rivadavia F., Fleischmann A. 2015. Drosera magnifica (Droseraceae): the largest

697 New World sundew, discovered on Facebook. Phytotaxa 220:257-267. DOI:

698 10.11646/phytotaxa.220.3.4.

699 Hage M., Leroy P., Petersen AC. 2010. Stakeholder participation in environmental knowledge

700 production. Futures 42:254-264. DOI: 10.1016/J.FUTURES.2009.11.011.

701 Hart SG. 2006. Nasa-Task Load Index (NASA-TLX); 20 Years Later. Proceedings of the Human

702 Factors and Ergonomics Society Annual Meeting 50:904-908. DOI:

$70310.1177 / 154193120605000909$.

704 Hart SG., Staveland LE. 1988. Development of NASA-TLX (Task Load Index): Results of

705 Empirical and Theoretical Research. Advances in Psychology 52:139-183. DOI: 10.1016/S0166-

$706 \quad 4115(08) 62386-9$.

707 Hawthorne WD., Cable S., Marshall CAM. 2014. Empirical Trials of Plant Field Guides.

708 Conservation Biology 28:654-662. DOI: 10.1111/cobi.12232. 
709 Hung D. 2002. Situated cognition and problem-based learning: Implications for learning and

710 instruction with technology. Journal of Interactive Learning Research 13:393-414.

711 IBM Corp. 2016. IBM SPSS Statistics for Windows.

712 Irwin A. 1995. Citizen science: a study of people, expertise, and sustainable development

713 London: Routledge.

714 ISO 9241-11. 1998. Ergonomic requirements for office work with visual display terminals

715 (VDTs) - Part 11: Guidance on usability. Available at

716 https://www.iso.org/obp/ui/\#iso:std:iso:9241:-11:ed-1:v1:en (accessed February 25, 2017).

717 Jonassen DH. 2000. Toward a design theory of problem solving. Educational Technology

718 Research and Development 48:63-85. DOI: 10.1007/BF02300500.

719 Kahn PH., Severson RL., Ruckert JH. 2009. The Human Relation With Nature and

720 Technological Nature. Current Directions in Psychological Science 18:37-42. DOI:

$721 \quad 10.1111 /$ j.1467-8721.2009.01602.x.

722 Lamberts K., Koen. 1995. Categorization under time pressure. Journal of Experimental

723 Psychology: General 124:161-180. DOI: 10.1037/0096-3445.124.2.161.

724 Lave J., Wenger E. 1991. Situated learning: Legitimate peripheral participation. Cambridge:

725 Cambridge University Press.

726 Lavie N. 1995. Perceptual load as a necessary condition for selective attention. Journal of

727 Experimental Psychology 21:451-68.

728 Leggett R., Kirchoff BK. 2011. Image use in field guides and identification keys: review and

729 recommendations. AoB Plants 2011:plr004. DOI: 10.1093/aobpla/plr004. 
730 Leow RP., Morgan-Short K. 2004. To Think Aloud or Not to Think Aloud: The Issue of

731 Reactivity in SLA Research Methodology. Studies in Second Language Acquisition 26:35-57.

732 DOI: $10.1017 / \mathrm{S} 0272263104026129$.

733 Lobanov A. 2003.Keys to beetles and biological diagnostics. Available at

734 http://www.zin.ru/Animalia/Coleoptera/eng/syst8.htm

735 Logan G. 2002. An instance theory of attention and memory. Psychological Review 109(2):376736400.

737 McDonald S., Edwards HM., Zhao T. 2012. Exploring Think-Alouds in Usability Testing: An

738 International Survey. IEEE Transactions on Professional Communication 55:2-19. DOI:

739 10.1109/TPC.2011.2182569.

740 Miller-Rushing A., Primack R. 2012. The history of public participation in ecological research.

741 Frontiers in Ecology and the Environment 10:285-290.

742 Mooney HA., Duraiappah A., Larigauderie A. 2013. Evolution of natural and social science

743 interactions in global change research programs. Proceedings of the National Academy of

744 Sciences 110:3665-3672. DOI: 10.1073/pnas.1107484110.

745 Morse DR., Tardival GM., Spicer J. 1996. A Comparison of the Effectiveness of a Dichotomous

746 Key and a Multi-Access Key to Woodlice. Available at

747 http://kar.kent.ac.uk/21343/1/WoodliceMorse.pdf

748 Pike MF., Maior HA., Porcheron M., Sharples SC., Wilson ML. 2014. Measuring the Effect of

749 Think Aloud Protocols on Workload using fNIRS. Proceedings of the 32nd annual ACM 
750 conference on Human factors in computing systems - CHI '14:3807-3816. DOI:

$751 \quad 10.1145 / 2556288.2556974$.

752 Raddick MJ., Bracey G., Gay PL., Lintott CJ., Murray P., Schawinski K., Szalay AS.,

753 Vandenberg J. 2010. Galaxy Zoo: Exploring the Motivations of Citizen Science Volunteers.

754 Astronomy Education Review 9. DOI: 10.3847/AER2009036.

755 Riesch H., Potter C. 2014. Citizen science as seen by scientists: Methodological, epistemological 756 and ethical dimensions. Public Understanding of Science 23:107-20. DOI:

$757 \quad 10.1177 / 0963662513497324$.

758 Scharf ST. 2008. Identification Keys, the "Natural Method," and the Development of Plant

759 Identification Manuals. Journal of the History of Biology 42:73-117. DOI: 10.1007/s10739-008$760 \quad 9161-0$.

761 Schrope M. 2013. Solving tough problems with games. Proceedings of the National Academy of 762 Sciences 110:7104-6. DOI: 10.1073/pnas.1306643110.

763 Siddharthan A., Lambin C., Robinson A-M., Sharma N., Comont R., O’Mahony E., Mellish C.,

764 Van der Wal R. 2016. Crowdsourcing Without a Crowd. ACM Transactions on Intelligent

765 Systems and Technology 7:1-20. DOI: 10.1145/2776896.

766 Silvertown J. 2009. A new dawn for citizen science. Trends in Ecology \& Evolution 24:467-71.

767 DOI: $10.1016 /$ j.tree.2009.03.017.

768 Silvertown J., Harvey M., Greenwood R., Dodd M., Rosewell J., Rebelo T., Ansine J.,

769 McConway K. 2015. Crowdsourcing the identification of organisms: A case-study of iSpot.

770 ZooKeys 480:125-46. DOI: 10.3897/zookeys.480.8803. 
771 Sol J., Beers PJ., Wals AEJ. 2013. Social learning in regional innovation networks: trust,

772 commitment and reframing as emergent properties of interaction. Journal of Cleaner Production

773 49:35-43. DOI: 10.1016/j.jclepro.2012.07.041

774 Stevenson RD., Haber WA., Morris RA. 2003. Electronic field guides and user communities in

775 the eco-informatics revolution. Ecology and Society 7:3.

776 Stucky JM. 1984. Comparison of Two Methods of Identifying Weed Seedlings. Weed Science

777 32:598-602. DOI: 10.2307/4043974.

778 Sullivan BL., Wood CL., Iliff MJ., Bonney RE., Fink D., Kelling S. 2009. eBird: A citizen-based

779 bird observation network in the biological sciences. Biological Conservation 142:2282-2292.

780 DOI: 10.1016/j.biocon.2009.05.006.

781 Swanson A., Kosmala M., Lintott C., Packer C. 2016. A generalized approach for producing,

782 quantifying, and validating citizen science data from wildlife images. Conservation Biology

783 30:520-531. DOI: 10.1111/cobi.12695.

784 Thompson LA., Massaro DW. 1989. Before you see it, you see its parts: evidence for feature

785 encoding and integration in preschool children and adults. Cognitive Psychology 21:334-62.

786 Treisman AM., Gelade G. 1980. A feature-integration theory of attention. Cognitive Psychology

787 12:97-136. DOI: 10.1016/0010-0285(80)90005-5.

788 Wagner HR., Glaser BG., Strauss AL. 1968. The Discovery of Grounded Theory: Strategies for

789 Qualitative Research. Social Forces 46:555. DOI: 10.2307/2575405. 
790 Van der Wal R., Anderson H., Robinson A., Sharma N., Mellish C., Roberts S., Darvill B.,

791 Siddharthan A. 2015. Mapping species distributions: A comparison of skilled naturalist and lay

792 citizen science recording. Ambio 44:584-600.

793 Van der Wal R., Sharma N., Mellish C., Robinson A., Siddharthan A. 2016. The role of

794 automated feedback in training and retaining biological recorders for citizen science.

795 Conservation Biology 30:550-561. DOI: 10.1111/cobi.12705.

796 Walter DE., Winterton S. 2007. Keys and the crisis in taxonomy: extinction or reinvention?

797 Annual Review of Entomology 52:193-208. DOI: 10.1146/annurev.ento.51.110104.151054.

798 Wills AJ., Inkster AB., Milton F. 2015. Combination or Differentiation? Two theories of

799 processing order in classification. Cognitive Psychology 80:1-33. DOI:

$800 \quad 10.1016 / \mathrm{j} \cdot \operatorname{cog} p s y c h .2015 .04 .002$.

801 Winterton S., Guek HP., Brooks S. 2012. A charismatic new species of green lacewing

802 discovered in Malaysia (Neuroptera, Chrysopidae): the confluence of citizen scientist, online

803 image database and cybertaxonomy. ZooKeys 214:1-11. DOI: 10.3897/zookeys.214.3220.

804 Young KA. 2005. Direct from the source: the value of 'think-aloud' data in understanding

805 learning. Journal of Educational Enquiry, 6:19-33.

806 


\section{Table $\mathbf{1}$ (on next page)}

Comparison of characteristics of different identification tools evaluated in this study. 


\begin{tabular}{|c|c|c|c|}
\hline Characteristics & $\begin{array}{l}\text { Field guide } \\
\text { (Control) }\end{array}$ & Feature selection & Decision tree \\
\hline $\begin{array}{l}\text { Type of identification } \\
\text { key }\end{array}$ & $\begin{array}{l}\text { Paper-based single } \\
\text { access (dichotomous/ } \\
\text { polytomous) }\end{array}$ & $\begin{array}{l}\text { Interactive multi- } \\
\text { access }\end{array}$ & $\begin{array}{l}\text { Interactive single } \\
\text { access, (dichotomous/ } \\
\text { polytomous) }\end{array}$ \\
\hline $\begin{array}{l}\text { Order of decision } \\
\text { making }\end{array}$ & $\begin{array}{l}\text { Partitioning species } \\
\text { into biologically } \\
\text { informed } \\
\text { subcategories }\end{array}$ & $\begin{array}{l}\text { Open choice selection } \\
\text { of visual features }\end{array}$ & $\begin{array}{l}\text { Directed by interface: } \\
\text { Easy visual features } \\
\text { decided first, and } \\
\text { harder features later } \\
\text { on }\end{array}$ \\
\hline Identification mode & $\begin{array}{l}\text { Visual comparison of } \\
\text { all species }\end{array}$ & $\begin{array}{l}\text { Interactive filtering } \\
\text { out of species that do } \\
\text { not match selected } \\
\text { features }\end{array}$ & $\begin{array}{l}\text { Interactive filtering } \\
\text { out of species that do } \\
\text { not match selected } \\
\text { features }\end{array}$ \\
\hline
\end{tabular}

Table 1 Comparison of characteristics of different identification tools evaluated in this 


\section{Figure 1}

Field guide.

Source: Bumblebee Conservation Trust (http://bumblebeeconservation.org) 
Bumblebees are large, hairy and colourful, with a distinctive 6umbling flight and constant 6uzz

Follow these simple steps. . . to learn how to identify the bumblebees you see in your garden and out in the countryside:
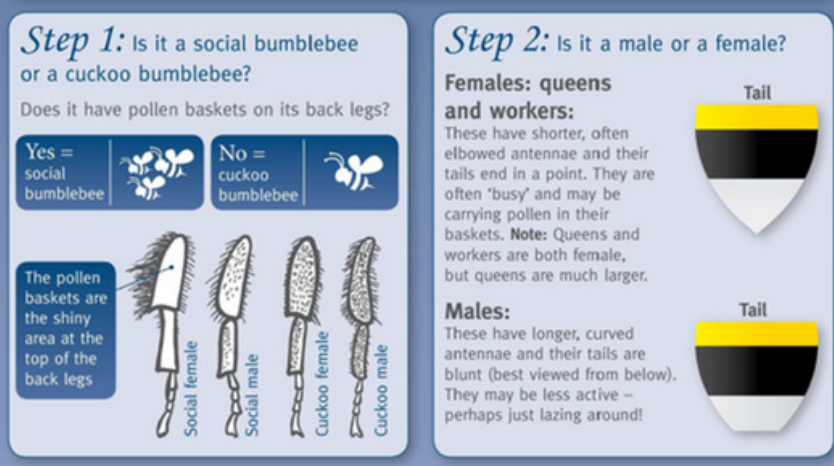

Step 3: What colour tail does it have? Which common social species could it be...

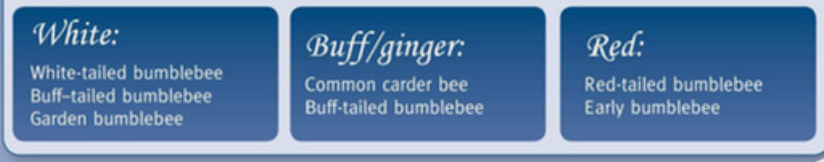

Step 4: Look closely. What coloured bands does it have and where are they?

See if the descriptions of the common bumblebees match with the bumblebee can fade by late summer.

If you're sure it's not there - Check if it could be a less common or rare species.

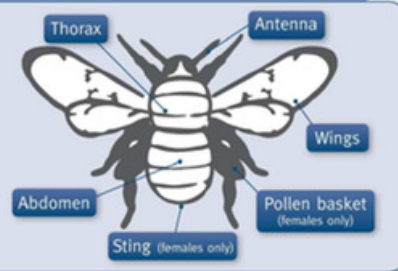

\section{Common 6umblebees}

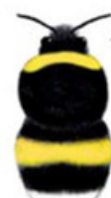

$\Delta$

White-tailed bumblebee Bombus lucorum A common bee, distinguished from the similar buff-tailed bumblebee by a pure-wite tail and two lemon yellow bands. Males have a yellow face. The queen and workers do not have a yellow band at the
bottom of the thorax (f yours does, try the garden

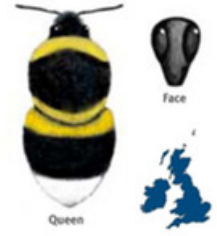

Garden bumblebee Bombus hortorum A very long-tongued species with a white tail and yellow bands, including one at the rear of the thorax
Has a longet thorsellike' face than the smaller heath Has a longet horse-like' face har

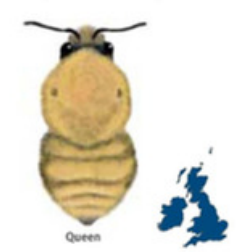

Common carder bee Bombus pascuorum bees hav Peerf reviewing PDF ' $(2018$

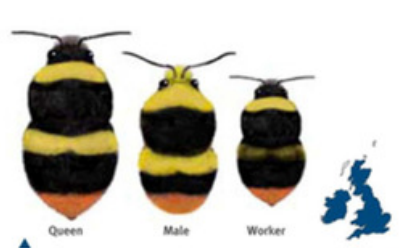

Early bumblebee Bombus pratorum common small bee with an orangey-red tail. Has one or two yellow bands and males have

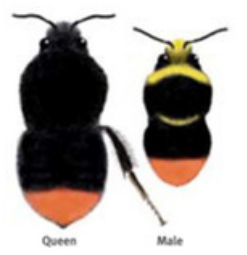

Red tailed bumblebee Bombus lapitorit Black bee with a red tail. Males have a yellow face 8:05:28277:1:0:NEW 15 Oct 2018)

Common 6umblebees

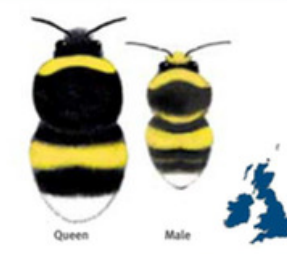

White-tailed bumblebee Bombus lucorum A common bee, distinguished from the similar ouff-tailed bumblebee by a pure-white tail and two queen and workers do not have a yellow band at the sottom of the thorax if yours does, try the garden cumblebee).

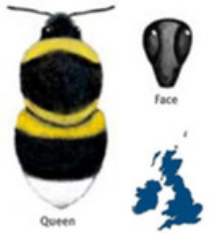

Garden bumblebee Bombus hortorum A very long-tongued species with a white tail and yellow bands, inctuding one at the rear of the thorax. Has a longer 'horse-like' face than the smaller heath bumblebee (view from front).

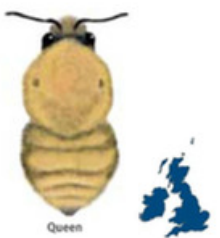

Common carder bee Bombus pascuorum The only common brown bumblebee. Rarer carder bees have little or no black hair on the abdomep. atthough you need to look closely.
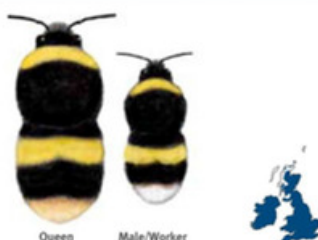
Buff-tailed bumblebee Bombus terrestris Queens and males usually have buff tails but of buff at the front margin. Yellow bands stighth darkestdinties than in the white talled bumblebee.

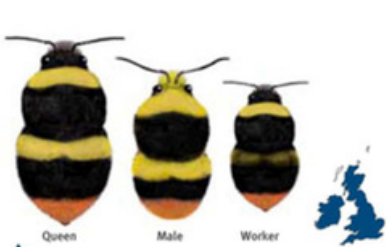

Early bumblebee Bombus pratorum A common small bee with an orangey-red tail.
Has one or two yellow bands and males have a yellow face. Rarely seen after July.

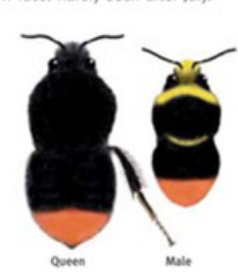

Red-tailed bumblebee Bombus lapidarius Black bee with a red tail. Males have a yellow face Females can be distinguished from the much raref red-shanked carder bee by black hairs of pollen basket on hind legs.

Buff-tailed bumblebee Bombus terrestris Queens and males usually have buff tails but workers tails are largely white, usually with a hint of buff at the front margin. Yellow bands slightly 
Figure 2

Decision tree tool.

Workflow from (a) to (d). The order of selections is "Mostly ginger/brown with some black or brown" in (a) -> "2" in (b) -> "Common Carder Bee" in (c).

\section{All Bees - Colours}

- Which description best matches the bee? (keep in mind colours fade as bees age)

- Black and yellow with a white tail

- Black and yellow with a red/orange tail

- Mostly black with a red/orange tail

- Ginger/brown and black with a white tail

- Mostly ginger/brown with some black or brown

- Mostly yellow with some black or brown

- All black a

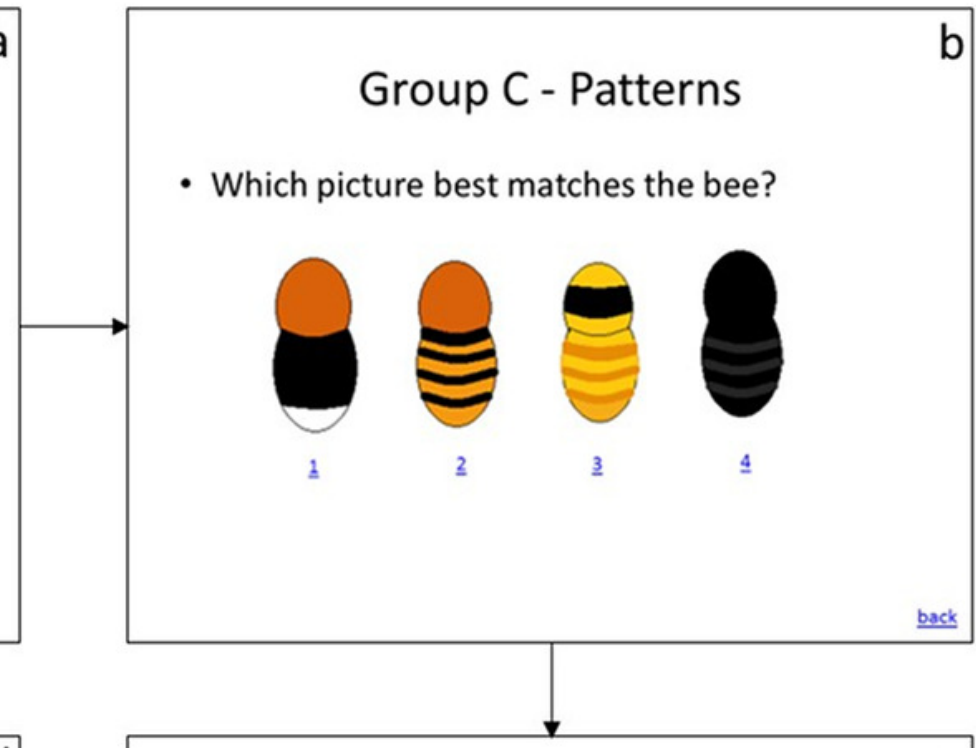

Common carder bee (Bombus pascuorum)

- A very common bee in the UK, easily confused with other brown/ginger bees however these are far less common.

- Queens, workers and males are almost completely brown or ginger. However, the shade varies significantly, depending on the location. Some have abdomens which are very dark, while the abdomens of others can be quite light. It is the only common UK bumblebee that is mostly brown or ginger.

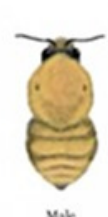

Mak

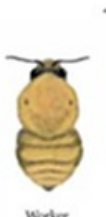

worker

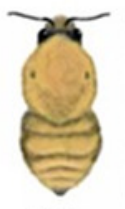

Qum

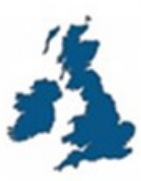

d

Now choose one of these species, look carefully for ${ }^{C}$ the relevant features that can separate these hard to distinguish species...

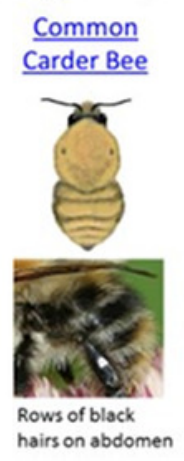

Brown-banded Carder Bee

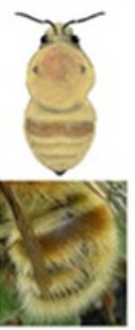

lighter hairs on abdomen, these two require microscopic examination to separate b 
Figure 3

Feature selection tool.

The final selection of a Red-tailed cuckoo bumblebee, achieved through the selected drop down menus on the left, which have shaded out species images that do not match the filters list in the center. The description of the selected species is on the right.

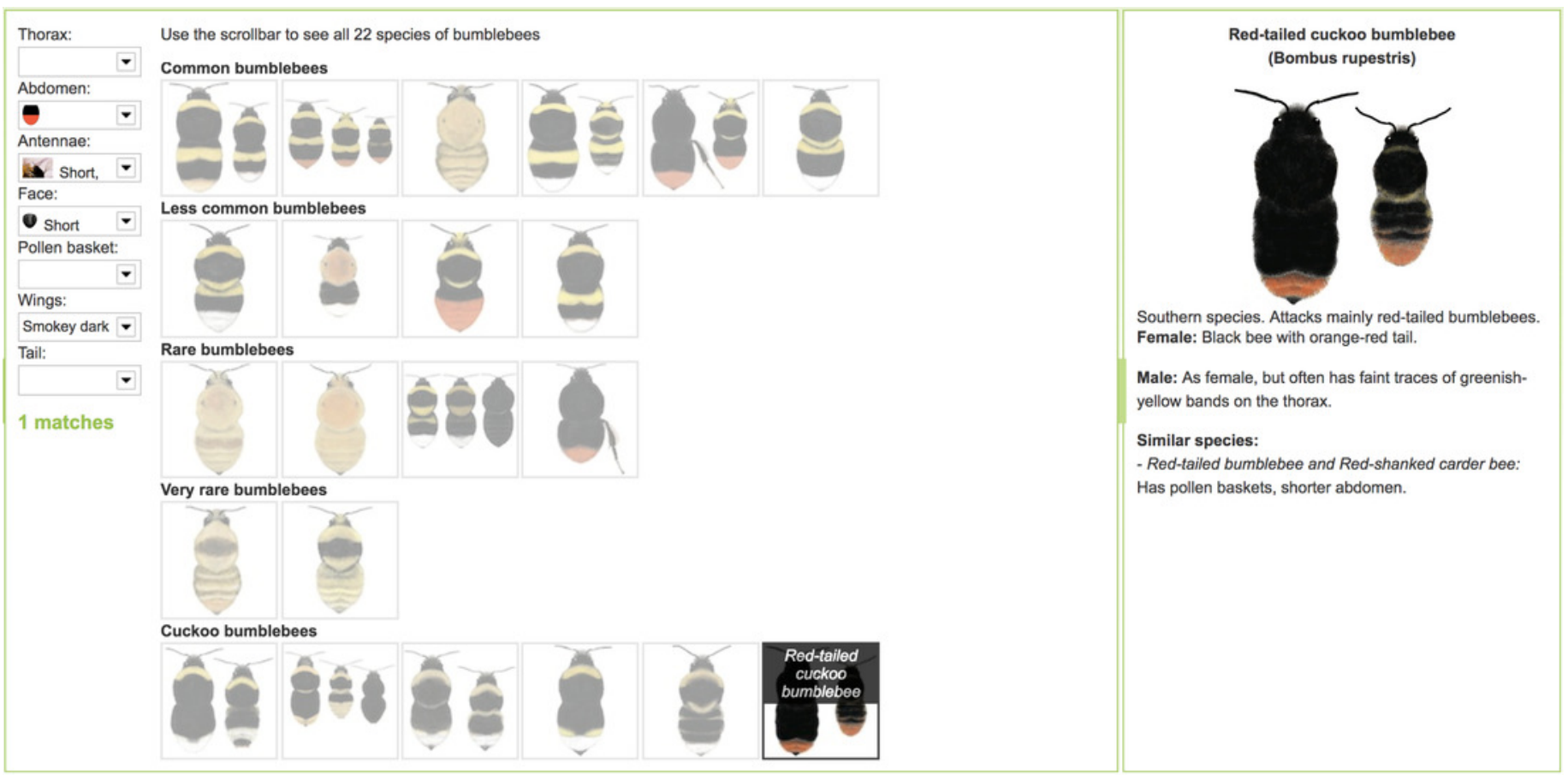




\section{Figure 4}

Quantitative analysis graphs.

(a) Mean ( \pm se) accuracy (0-1), (b) Mean Time taken (in sec) and (c) Mean Workload scores (scale 0-100) for each of the three studied interface types, for easy (grey bars) and difficult images (black bars) separately.

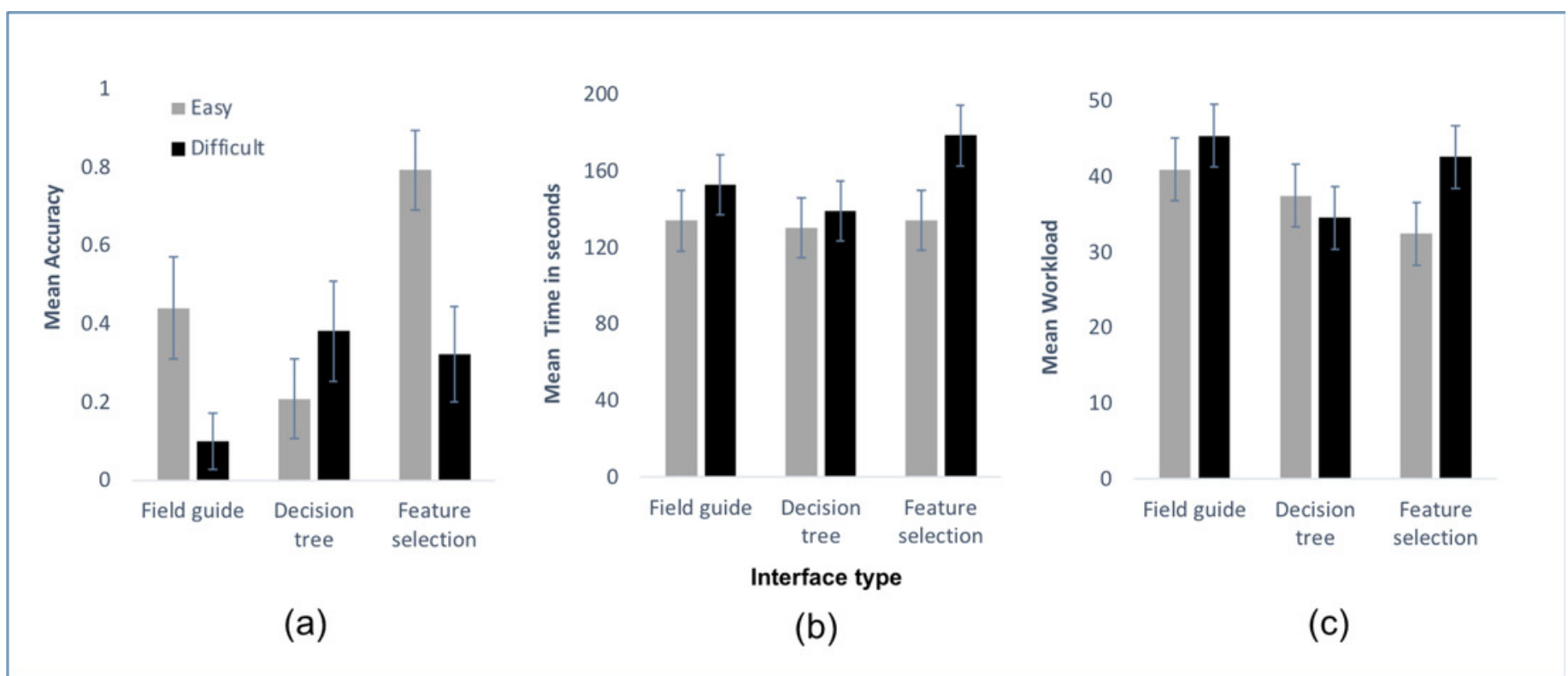

